\title{
Moderately Oxidized Oils and Dietary Zinc and $\alpha$-Tocopheryl Acetate Supplementation: Effects on the Oxidative Stability of Rabbit Plasma, Liver, and Meat
}

\author{
Alba Tres, * Ricard Bou, Rafael Codony, and Francesc Guardiola \\ Nutrition and Food Science Department, XaRTA-INSA, Faculty of Pharmacy, University of Barcelona, \\ Avinguda Joan XXIII s/n, 08028 Barcelona, Spain
}

\begin{abstract}
The aim of this study was to assess the alterations in plasma, liver, and meat oxidative stability and $\alpha$-tocopherol content when moderately oxidized sunflower oils were added to feeds and when feeds were supplemented with $\alpha$-tocopheryl acetate $(100 \mathrm{mg} / \mathrm{kg})$ and $\mathrm{Zn}(200 \mathrm{mg} / \mathrm{kg})$. The effects of cooking the meat and its subsequent refrigeration were also studied. When the content of primary oxidation compounds of the oil was high, rabbit plasma, liver, and meat $\alpha$-tocopherol content was reduced and meat susceptibility to oxidation increased. The addition of oil with a high content of secondary oxidation compounds (oil heated at $140^{\circ} \mathrm{C}, 31 \mathrm{~h}$ ) to feed also led to an increase in meat susceptibility to oxidation, although it presented an $\alpha$-tocopherol content similar to that of nonheated oil. Feed supplementation with $\alpha$-tocopheryl acetate increased tissue $\alpha$-tocopherol content and improved the oxidative stability of liver and meat. However, in the latter, it was less effective when oil heated at $55^{\circ} \mathrm{C}$ was added.
\end{abstract}

KEYWORDS: Heated oils; zinc supplementation; $\alpha$-tocopherol; meat oxidation; cooking; TBA value; FOX; lipid hydroperoxides

\section{INTRODUCTION}

There is currently interest in supplementing animal feed with unsaturated fats. This procedure seeks to improve the nutritional value of meat and other animal products not only by increasing the content of polyunsaturated fatty acids (PUFA) but also by reducing the $n-6 / n-3$ ratio (1).

However, feed and animal producers should consider not only the fatty acid (FA) composition of fat ingredients added to feeds but also their degree of oxidation because unsaturated fats are prone to oxidization. At low temperatures, for instance, during the storage of these ingredients, the content of lipid hydroperoxides (LHP) increases until reaching a plateau (2). Thereafter, LHP decompose into secondary oxidation compounds. At high temperatures, the degradation of LHP is accelerated, so mostly secondary oxidation compounds are found in fat, as well as some polymeric compounds (2). High temperatures are achieved during common processes such as refining or frying. In fact, several fat co- and byproducts from the food chain obtained from processes involving high temperatures are currently used as animal feed ingredients (3).

The addition of heated oils to animal feed does not lead to toxic effects when the fat content of the diets is not above the recommended dose for each animal species and when oil contains $<25 \%$ polar compounds (4). Some effects on digestibility occur when the polymer content of fats is high (5), but it should be taken into account that several detrimental biological effects have been reported for some oxidation compounds $(6-8)$. These effects are

*Corresponding author (phone +34-93-4024508; fax +34-934035931; e-mail atres@ub.edu). a result of the presence of these compounds in the gastrointestinal tract $(5,8)$ and in tissues, regardless of whether they are formed in vivo or absorbed from diet $(7,8)$. Whereas the absorption of some secondary oxidation compounds is possible $(4,5,7,9)$, the absorption of intact LHP is more limited because they seem to be decomposed in the gastrointestinal tract to compounds containing hydroxy, keto, or epoxy groups, which can be absorbed (9).

Therefore, evaluating the oxidation of fat is essential before its addition to feeds otherwise it might contain a high amount of primary and/or secondary oxidation compounds that may be absorbed by the animal. This absorption would alter tissue composition and favor its susceptibility to oxidation, which, apart from the negative biological effects related to oxidation compounds, would lead to a decrease in shelf life and meat nutritional quality $(1,10)$. However, the oxidative status of fat products added to feeds is not always globally assessed (3). Scientific literature is lacking in studies dealing with the incorporation of moderately oxidized oils in rabbit feeds. Several studies in which heated oils were added to chicken feed reported reduced oxidative stability of tissues (11). These findings were attributed to the decrease in tissue $\alpha$-tocopherol $(\alpha \mathrm{T})$ content caused by $\alpha \mathrm{T}$ reaction with oxidation compounds in diets, in the gastrointestinal tract or in tissues $(11,12)$.

Apart from the fat added to feeds, other factors such as meat mineral content, meat processing, and its storage conditions influence meat oxidation (10). Meat is a source of minerals with high bioavailability, and furthermore, some of them are involved in oxidation processes both in vivo and post-mortem $(1,10)$. Minerals such as Fe might act as a pro-oxidant, especially after 
cooking (10). Others such as Se or $\mathrm{Zn}$ form part of antioxidant enzymes, such as superoxide dismutase and glutathione peroxidase in some animal species (1); thus, it is interesting to study whether the dietary supplementation with zinc alters meat oxidation. Dietary supplementation with $\alpha$-tocopheryl acetate (TA) has been recommended as a measure to protect meat from oxidation during processing, cooking, and storage, especially when feeds include unsaturated fats (1). However, the effect of antioxidant compounds added to feeds might be altered by the concomitant presence of primary and/or secondary lipid oxidation compounds.

Thus, the aim of this study was to assess the effect of supplementing rabbit feed with moderately oxidized sunflower oils (SO) with different contents of primary and secondary oxidation compounds. The effects of dietary supplementation with TA $(100 \mathrm{mg} / \mathrm{kg})$ and $\mathrm{Zn}(200 \mathrm{mg} / \mathrm{kg})$ on $\alpha \mathrm{T}$ content and on the oxidation and susceptibility to oxidation of rabbit plasma, liver, and meat were also examined. In addition, it was also studied how these dietary factors affected meat $\alpha \mathrm{T}$ content and oxidation after cooking and after refrigeration of the cooked meat.

\section{MATERIALS AND METHODS}

Thermal Treatment of Oils. An unrefined SO was divided in three aliquots to perform the thermal treatment (Table 1). The first aliquot, named fresh sunflower oil (FSO), was not subjected to thermal treatment. A second aliquot, named peroxidized sunflower oil (PSO), was heated at $55^{\circ} \mathrm{C}$ for $245 \mathrm{~h}$ in a heat exchanger under agitation. The third aliquot, named oxidized sunflower oil (OSO), was heated in a direct heating fryer at $140{ }^{\circ} \mathrm{C}$ for $31 \mathrm{~h}$. Immediately after the thermal treatments, butyl hydroxytoluene was added to the oils at $100 \mathrm{mg} / \mathrm{kg}$ to prevent development of oxidation during oil storage. Taking into account the antioxidants included in the vitamin premix of basal feeds (Table 1), the global antioxidant amount included in the basal feeds was $7 \mathrm{mg}$ (butyl hydroxytoluene + butyl hydroxyanisole + ethoxyquin) $/ \mathrm{kg}$ of feed, which is much lower than the upper limit allowed by European Regulation (13).

The oxidation status of oils was evaluated by determining their peroxide value [DGF method C-VI 6a (14)], their LHP content using the noninduced ferrous oxidation-xylenol orange (FOX) method (15), and their $p$-anisidine value [AOCS official method Cd 18-90 (16)]. The polymer content of oils [DGF method C-III 3d $(<3 \%)$ (17), IUPAC 2508 $(>3 \%)(18)]$ and their $\alpha \mathrm{T}$ content (19) were also determined. Results are shown in Table 1. The level of oxidation reached was below the limits established in most regulations for discarding frying oils (20).

Animals and Diets. The diets were prepared and the animals were housed in the Animal Science Department at the Polytechnic University of Valencia (Spain). This study received prior approval from the Animal Protocol Review Committee of the Polytechnic University of Valencia, and all animal housing, husbandry, and slaughtering conditions were in agreement with current European Union guidelines.

Twelve dietary treatments were prepared from a basal diet by the combination of the dietary factors of interest, following a factorial design $(3 \times 2 \times 2)$, replicated four times: 3 types of oxidized sunflower oil (FSO, PSO, and OSO) added to feeds at $3 \%(\mathrm{w} / \mathrm{w}) ; 2$ doses of TA $(0$ or $100 \mathrm{mg}$ $\mathrm{TA} / \mathrm{kg}$ of feed) and 2 doses of $\mathrm{Zn}$ ( 0 or $200 \mathrm{mg} / \mathrm{kg}$, added as zinc oxide).

Samples. Oils were taken immediately after the thermal treatment, and peroxide value and $p$-anisidine value were determined within the following $6 \mathrm{~h}$. Oil samples were stored in glass vials closed with Teflon caps, filled with $\mathrm{N}_{2}$, and frozen at $-25{ }^{\circ} \mathrm{C}$ until the rest of the analyses were performed.

Feed samples were taken at the end of the feeding trial. Feeds were ground and vacuum-packed in high-barrier multilayer bags (Cryovac BB325; permeability to $\mathrm{O}_{2} 25 \mathrm{~cm}^{3} \mathrm{~m}^{-2}$ day $^{-1}$ bar $^{-1}$ at $23{ }^{\circ} \mathrm{C}$ and $0 \%$ relative humidity (RH), ASTMD-3985; Cryovac Europe, Sealed Air S. L., Sant Boi de Llobregat, Spain; approximately $15 \mathrm{~g}$ of feed/bag) and stored at $-25^{\circ} \mathrm{C}$ until analysis. Feed analyses were performed in triplicate.

Two hundred and eighty-eight rabbits (cross of New Zealand and Californian rabbit) were weaned at 28 days; they were randomly divided into 48 cages ( 12 dietary treatments, 4 replicates, 6 rabbits per cage) and fed ad libitum with the corresponding experimental diet. At 63 days of age, rabbits were electrically stunned and killed by cutting carotids and jugulars. From four rabbits in each cage, $20 \mathrm{~mL}$ of blood per animal was collected in heparinized tubes and immediately centrifuged at $1450 \mathrm{~g}$ at $4{ }^{\circ} \mathrm{C}$ for $10 \mathrm{~min}$. Plasma samples from each cage were mixed and transferred into microtubes and stored at $-80{ }^{\circ} \mathrm{C}$ until analysis. Livers were immediately removed from carcasses and refrigerated for $5 \mathrm{~h}$. Then, the six livers from each cage were mixed, ground, vacuum-packed in highbarrier multilayer bags (Cryovac BB325; approximately $15 \mathrm{~g}$ of liver/bag), and stored at $-80^{\circ} \mathrm{C}$ until analysis. Carcasses were refrigerated for $24 \mathrm{~h}$ at $4{ }^{\circ} \mathrm{C}$. One leg was taken from each animal of each cage and was hand deboned. Meat from the six legs was mixed, ground, and divided into two parts: raw and cooked meat. Raw meat samples were vacuum-packed in high-barrier multilayer bags (Cryovac BB325; approximately $20 \mathrm{~g}$ of meat/ bag) and stored at $-25^{\circ} \mathrm{C}$ until analysis. For cooked meat samples, raw meat was vacuum-packed in high-barrier multilayer bags (Cryovac CN330; permeability to $\mathrm{O}_{2} 15 \mathrm{~cm}^{3} \mathrm{~m}^{-2}$ day $^{-1}$ bar $^{-1}$ at $23{ }^{\circ} \mathrm{C}$ and $0 \%$ RH (ASTMD-3985); approximately $5 \mathrm{~mm}$ of ground meat paste thickness and $20 \mathrm{~g}$ of meat $/ \mathrm{bag}$ ) and then cooked in a water bath at $78^{\circ} \mathrm{C}$ for $5 \mathrm{~min}$. Cooked meat samples were then stored at $-25^{\circ} \mathrm{C}$ until analysis, whereas refrigerated cooked meat samples were stored at $5^{\circ} \mathrm{C}$ for 62 days and then frozen at $-25^{\circ} \mathrm{C}$ until analysis.

Reagents and Standards. Thiobarbituric acid (TBA), $\alpha \mathrm{T}$, and cumene hydroperoxide (CHP) were obtained from Sigma-Aldrich (St. Louis, MO). Xylenol orange was purchased from Scharlab (Barcelona, Spain). Solvents used in $\alpha \mathrm{T}$ analysis, polymer content, $p$-anisidine value, and FOX method were of HPLC grade.

Determination of $\alpha \mathbf{T}$ in Feed, Plasma, Liver, and Meat. The content of $\alpha \mathrm{T}$ in feed, liver, and meat was determined after saponification by HPLC with fluorescence detection (21).

Plasma $\alpha \mathrm{T}$ content was measured by HPLC-UV detection, without a previous saponification step, as described in Tres et al. (22).

Susceptibility to Oxidation of Plasma, Liver, and Meat. To assess the susceptibility of plasma, liver, and meat to lipid oxidation, LHP were measured by the induced FOX method (23). In this procedure, a methanolic extract of samples is mixed with the FOX reagents in glass cuvettes capped with Teflon caps. The mixture (the final volume of the reaction mixture was always $2 \mathrm{~mL}$ ) is then incubated in the dark to induce LHP formation until absorbance at $560 \mathrm{~nm}$ is steady. Absorbance at $560 \mathrm{~nm}$ is measured with a spectrophotometer (Shimadzu UV-160A, Shimadzu, Kyoto, Japan), and the LHP value is determined by means of a calibration curve using CHP as standard.

The procedure used for plasma and liver samples was as described by Tres et al. (22). In these samples, only the LHP value reached at the end of the incubation period (final LHP) was measured (116 h for plasma; $90 \mathrm{~h}$ for liver), which was enough to assess the different susceptibilities to oxidation among samples.

For meat samples, a modification of the FOX method was used (24), because as explained in ref 24 preliminary tests showed that samples could have reached similar final LHP values in different ways due to their different susceptibilities to oxidation. Thus, apart from the final LHP value (at $216 \mathrm{~h}$ of incubation) (mmol of CHP equiv $/ \mathrm{kg}$ of meat), the induction time (IT, h), the maximum LHP value reached (MAXLHP, mmol of CHP equiv $/ \mathrm{kg}$ of meat), the time to reach the MAXLHP (TMAX, h), and the area under the LHP curve [AUC, (mmol of CHP equiv $/ \mathrm{kg}$ of meat $) \times \mathrm{h}$ ] were also determined. These parameters might provide a deeper insight into the evolution of oxidation in each sample (24).

Determination of TBA Value. The TBA value of rabbit meat was determined by an acid aqueous extraction method with third-derivative spectrophotometry (25). This method was also used to determine the TBA value of liver and plasma samples, using the modifications described in Tres et al. (22).

Statistics. One-way ANOVA was used to determine whether there were any differences in the $\alpha \mathrm{T}$ content and the oxidation parameters assessed in the oils added to feeds, as a result of heating conditions ( $n=9$, oils were analyzed in triplicate). Multifactor ANOVA was used to determine significant differences due to the dietary factors (degree of oil oxidation, TA and $\mathrm{Zn}$ supplementation) on the $\alpha \mathrm{T}$ content of feeds $(n=$ 36 ), and the $\alpha \mathrm{T}$ content, susceptibility to oxidation, and TBA values of plasma $(n=48)$, liver $(n=48)$, raw meat $(n=48)$, cooked meat $(n=48)$, and refrigerated cooked meat $(n=48)$. Multifactor ANOVA was used to 
Table 1. Thermal Treatment Applied to Oils Added to Feeds, Assessment of Oil Oxidation, Content of $\alpha$-Tocopherol in Oils, Feed, Plasma, Liver, and Meat, and Oxidation (TBA Value) and Susceptibility to Oxidation (FOX Values) of Plasma, Liver, and Meat for the Diets Containing Sunflower Oils with Different Degrees of Oxidation, plus Supplementation with $\alpha$-Tocopheryl Acetate $(0$ or $100 \mathrm{mg} / \mathrm{kg})$ and $\mathrm{Zn}(0 \text { or } 200 \mathrm{mg} / \mathrm{kg})^{a-c}$

\begin{tabular}{|c|c|c|c|c|c|c|c|}
\hline & \multicolumn{3}{|c|}{ added oil } & \multicolumn{2}{|c|}{$\mathrm{TA}(\mathrm{mg} / \mathrm{kg})$} & \multicolumn{2}{|c|}{$\mathrm{Zn}(\mathrm{mg} / \mathrm{kg})$} \\
\hline & FSO & PSO & OSO & 0 & 100 & 0 & 200 \\
\hline thermal treatment of oil & no treatment & $55^{\circ} \mathrm{C}, 245 \mathrm{~h}$ & $140^{\circ} \mathrm{C}, 31 \mathrm{~h}$ & & & & \\
\hline \multicolumn{8}{|l|}{ assessment of oil oxidation } \\
\hline peroxide value (mequiv of $\mathrm{O}_{2} / \mathrm{kg}$ of oil) & $10.4 \mathrm{y}$ & $83.0 \mathrm{z}$ & $9.8 x$ & & & & \\
\hline LHP content (mmol of CHP equiv/kg of oil) & $10.5 y$ & $89.0 \mathrm{z}$ & $5.84 x$ & & & & \\
\hline polymer content $(\%, w / w)$ & $2.8 \mathrm{x}$ & $2.7 x$ & $124.5 \mathrm{y}$ & & & & \\
\hline$p$-anisidine value & $0.09 x$ & $0.25 \mathrm{y}$ & $9.9 \mathrm{z}$ & & & & \\
\hline \multicolumn{8}{|l|}{$\alpha$-tocopherol content } \\
\hline oils (mg of $\alpha \mathrm{T} / \mathrm{kg}$ of oil) & $621.5 \mathrm{y}$ & $510.6 x$ & $605.1 x y$ & & & & \\
\hline feeds ( $\mathrm{mg}$ of $\alpha \mathrm{T} / \mathrm{kg}$ of feed) & $74.5 x y$ & $67.6 x$ & $77.4 \mathrm{y}$ & $33.7 x$ & $112.6 \mathrm{y}$ & 75.0 & 71.3 \\
\hline plasma (mg of $\alpha \mathrm{T} / \mathrm{L}$ of plasma) ${ }^{d}$ & $4.21 \mathrm{y}$ & $3.59 x$ & $4.02 x y$ & $2.40 x$ & $5.48 \mathrm{y}$ & 3.98 & 3.90 \\
\hline liver (mg of $\alpha \mathrm{T} / \mathrm{kg}$ of liver) & $10.1 \mathrm{y}$ & $8.0 x$ & $8.9 x y$ & $4.6 x$ & $13.5 y$ & 8.8 & 9.2 \\
\hline raw meat (mg of $\alpha \mathrm{T} / \mathrm{kg}$ of meat) & $2.82 y$ & $2.18 x$ & 2.72 y & $1.27 x$ & 3.88 y & 2.61 & 2.53 \\
\hline cooked meat (mg of $\alpha \mathrm{T} / \mathrm{kg}$ of meat) & $2.89 \mathrm{y}$ & $2.23 x$ & $2.77 \mathrm{y}$ & $1.33 x$ & $3.93 \mathrm{y}$ & 2.68 & 2.58 \\
\hline refrigerated cooked meat ( $\mathrm{mg}$ of $\alpha \mathrm{T} / \mathrm{kg}$ of meat) & $2.80 \mathrm{y}$ & $2.07 \mathrm{y}$ & $2.65 \mathrm{y}$ & $1.27 x$ & $3.75 \mathrm{y}$ & 2.53 & 2.48 \\
\hline \multicolumn{8}{|l|}{ oxidation (TBA value) } \\
\hline plasma ( $\mu \mathrm{g}$ of MDA/L of plasma) & nd & nd & nd & nd & nd & nd & nd \\
\hline $\operatorname{liver}^{e}(\mu \mathrm{g}$ of MDA $/ \mathrm{kg}$ of liver) & 64 & 59 & 57 & 64 y & $55 x$ & 60 & 60 \\
\hline raw meat ( $\mu \mathrm{g}$ of MDA/kg of meat) & 21 & 21 & 23 & 25 & 21 & 22 & 24 \\
\hline cooked meat ${ }^{f}(\mu \mathrm{g}$ of MDA $/ \mathrm{kg}$ of meat) & 29 & 33 & 27 & $36 \mathrm{y}$ & $23 x$ & $27 x$ & 32 y \\
\hline refrigerated cooked meat ( $\mu \mathrm{g}$ of MDA $/ \mathrm{kg}$ of meat) & 778 & 787 & 783 & 808 & 758 & 814 & 751 \\
\hline \multicolumn{8}{|l|}{ susceptibility to oxidation (FOX values) } \\
\hline plasma (final LHP, mmol of CHP equiv/L of plasma) & 0.044 & 0.048 & 0.045 & 0.047 & 0.044 & 0.046 & 0.045 \\
\hline liver (final LHP, mmol of CHP equiv/kg of liver) & 5.72 & 6.59 & 5.60 & 9.23 y & $2.71 x$ & 6.24 & 5.70 \\
\hline \multicolumn{8}{|l|}{ raw meat } \\
\hline $\mathrm{IT}^{d, f}(\mathrm{~h})$ & $118^{i} z$ & $38 x$ & $89^{i} \mathrm{y}$ & $10 x$ & $153^{i} y$ & $88^{i}$ & $75^{i}$ \\
\hline $\operatorname{MAXLHP}^{d, f}$ (mmol of CHP equiv $/ \mathrm{kg}$ of meat) & $0.41 x$ & $0.71 z$ & $0.55 y$ & $0.84 \mathrm{y}$ & $0.28 x$ & 0.55 & 0.56 \\
\hline $\operatorname{TMAX}^{d}(\mathrm{~h})$ & $144^{i} \mathrm{y}$ & $96 \mathrm{x}$ & $129^{i} \mathrm{y}$ & $58 x$ & $188^{i} y$ & $119^{i} \mathrm{x}$ & $127^{i} y$ \\
\hline final LHPd,f (mmol of CHP equiv/kg of meat) & $0.29 x$ & $0.52 z$ & $0.41 \mathrm{y}$ & $0.56 \mathrm{y}$ & $0.25 x$ & 0.39 & 0.42 \\
\hline $\mathrm{AUC}^{f}[(\mathrm{mmol}$ of CHP equiv $/ \mathrm{kg}$ of meat $) \times \mathrm{h}]$ & $62.2 x$ & $101.4 \mathrm{y}$ & $81.4 \mathrm{y}$ & $130 y$ & $33.2 x$ & 82.7 & 80.6 \\
\hline \multicolumn{8}{|l|}{ cooked meat } \\
\hline $\mathrm{IT}^{d, h}(\mathrm{~h})$ & $121.5^{i} \mathrm{y}$ & $64.8^{i} x$ & $114^{i} y$ & $16 x$ & $184^{i} y$ & $100^{i}$ & $100^{i}$ \\
\hline MAXLHP (mmol of CHP equiv $/ \mathrm{kg}$ of meat) & $0.44 x$ & $0.65 y$ & $0.48 x$ & $0.84 \mathrm{y}$ & $0.20 x$ & 0.52 & 0.52 \\
\hline $\operatorname{TMAX}^{g, h}(\mathrm{~h})$ & $135^{i}$ & $129^{i}$ & $135^{i}$ & $51 x$ & $215^{i} y$ & $132^{i}$ & $134^{i}$ \\
\hline final LHP ${ }^{d, h}$ (mmol of CHP equiv/kg of meat) & $0.35 x$ & $0.50 y$ & $0.37 y$ & $0.61 \mathrm{y}$ & $0.20 x$ & 0.40 & 0.41 \\
\hline AUC $[(\mathrm{mmol}$ of $\mathrm{CHP}$ equiv/ $/ \mathrm{kg}$ of meat $) \times \mathrm{h}]$ & $66.5 x$ & $88 \mathrm{y}$ & $69 x$ & $130 y$ & $19 x$ & 74 & 75 \\
\hline \multicolumn{8}{|l|}{ refrigerated cooked meat } \\
\hline $\mathrm{IT}^{d, e}(\mathrm{~h})$ & $120^{i}$ & 61.7 & $109.6^{i}$ & $14.2 x$ & $180^{i} y$ & $86^{i} x$ & $108^{i} y$ \\
\hline MAXLHP (mmol of CHP equiv/kg of meat) & $0.38 x$ & $0.63 y$ & $0.43 x$ & $0.79 y$ & $0.17 x$ & 0.51 & 0.45 \\
\hline $\operatorname{TMAX}^{h}(\mathrm{~h})$ & $138^{i} y$ & $109.5 x$ & $135^{i} x$ & $56 x$ & $199^{i} y$ & $123^{i}$ & $132^{i}$ \\
\hline final LHP (mmol of CHP equiv/kg of meat) & $0.25 x$ & $0.47 y$ & $0.29 x$ & $0.54 \mathrm{y}$ & $0.14 x$ & 0.37 & 0.31 \\
\hline AUC $[(\mathrm{mmol}$ of CHP equiv $/ \mathrm{kg}$ of meat $) \times \mathrm{h}]$ & $54.4 x$ & $95 \mathrm{y}$ & $61.7 x$ & $119 y$ & $21.4 x$ & 73.6 & 67.3 \\
\hline
\end{tabular}

${ }^{a}$ Abbreviations: FSO, fresh sunflower oil; PSO, peroxidized sunflower oil; OSO, oxidized sunflower oil; TA, $\alpha$-tocopheryl acetate; $\alpha$ T, $\alpha$-tocopherol; CHP, cumene hydroperoxide; TBA, thiobarbituric acid; MDA, malondialdehyde; LHP, lipid hydroperoxide; IT, induction time; MAXLHP, maximum LHP value; TMAX, time to reach the MAXLHP; AUC, area under the curve; nd, not detected. Values in the same row for a certain factor bearing no common letters $(\mathrm{x}-\mathrm{z})$ are statistically different $(P \leq 0.05)$. $P$ values were obtained from one-way ANOVA for oils $(n=9)$ and from multifactor ANOVA for feeds, plasma, liver, and meats ( $n=36$ for feeds, $n=48$ for plasma, liver, and meats). Letters were obtained by means of the Scheffé test $(\alpha=0.05) .{ }^{b}$ Ingredients of diets: beet pulp, $28 \%$; alfalfa, $25 \%$; sunflower meal, $20 \%$; wheat bran, $15 \%$; soybean meal, $6 \%$; fat (FSO, PSO, or OSO according to each dietary treatment), $3 \%$; dicalcium phosphate, $1.2 \%$; sodium chloride, $0.5 \%$; L-lysine, $0.3 \%$; calcium carbonate, $0.2 \%$; DL-methionine, $0.1 \%$; L-threonine, $0.1 \%$; robenidine, $0.1 \%$ (not included in the feeds given to rabbits during their last week of life); sodium selenite, $0.1 \mathrm{mg} / \mathrm{kg}$ of feed; trace mineral-vitamin mix L-510 (Trouw Nutrition, Spain), $0.5 \%$ [supplied the following per $\mathrm{kg}$ of feed: $290 \mathrm{mg}$ of magnesium oxide; $330 \mathrm{mg}$ of sodium; $275 \mathrm{mg}$ of sulfur; $700 \mu \mathrm{g}$ of cobalt carbonate monohydrate; $10 \mathrm{mg}$ of copper sulfate pentahydrate; $76 \mathrm{mg}$ of ferrous sulfate monohydrate; $20 \mathrm{mg}$ of manganese oxide; $59.2 \mathrm{mg}$ of zinc oxide; $1.25 \mathrm{mg}$ of potassium iodide; $8375 \mathrm{IU}$ of vitamin A; $750 \mathrm{IU}$ of vitamin D3; $20 \mathrm{mg}$ of $\alpha$-tocopherol; $1 \mathrm{mg}$ of vitamin B1; $2 \mathrm{mg}$ of vitamin B2; $1 \mathrm{mg}$ of vitamin B6; $1 \mathrm{mg}$ of vitamin K; $20 \mathrm{mg}$ of niacin; $250 \mathrm{mg}$ of choline chloride; $4 \mathrm{mg}$ of butylated hydroxyanisole + ethoxyquin; $2.5 \mathrm{mg}$ of flavophospholipol $(80 \mathrm{mg} / \mathrm{kg})] .{ }^{c}$ Values correspond to means $(n=9)$ for oils, and to least-squares means obtained from multifactor ANOVA for the main factors for feed $(n=36)$, plasma $(n=48)$, liver $(n=48)$, and meat $(n=48) .{ }^{d}$ Interaction between oil added and TA supplementation, significant at $P \leq 0.05$. See Table 2. ${ }^{e}$ Interaction between TA and $\mathrm{Zn}$ supplementation, significant at $P \leq 0.05 .{ }^{f}$ Interaction between oil added and $\mathrm{Zn}$ supplementation, significant at $P \leq 0.05$. See Table 4. ${ }^{g}$ Interaction between cooking and oil added, significant at $P \leq 0.05$. ( $n=96$, including raw and cooked meat). ${ }^{h}$ Interaction between cooking or refrigeration and TA supplementation, significant at $P \leq 0.05[n=96$, for the effect of cooking (raw + cooked meat); $n=96$ for the effect of refrigerating cooked meat (cooked + refrigerated cooked meats)]. ${ }^{i}$ If oxidation had not increased in the samples by the end of reaction time, the final time ( $216 \mathrm{~h}$ ) was considered to be the TMAX for these samples. Therefore, some values could be underestimated.

determine whether the $\alpha \mathrm{T}$ content, FOX, and TBA values differed between plasma, liver, and raw meat samples as a result of the studied dietary factors $(n=144)$. Multifactor ANOVA was used to determine whether there were significant differences in the $\alpha \mathrm{T}$ content, and FOX and TBA values of meat as a result of cooking $(n=96$, raw vs cooked meat samples) and of refrigerating cooked meat ( $n=96$, cooked vs refrigerated cooked meat samples). Interactions between more than two factors were ignored. Least-squares means for the main factors that had a significant effect were separated by Scheffé test. Pearson correlation coefficients were calculated between the $\alpha \mathrm{T}$ content and FOX and TBA values in plasma, liver, and meat and between raw, cooked, and refrigerated cooked meat. In all cases, $P \leq 0.05$ was considered to be significant. Statistical analysis was performed using SPSS 15.0 (SPSS Inc., Chicago, IL) software. 


\section{RESULTS AND DISCUSSION}

Plasma, Liver, and Raw Meat. Plasma, liver, and meat oxidation was assessed by means of determining the TBA value, which measures their malondialdehyde (MDA), a secondary oxidation compound, content (25). In addition, the susceptibility of these samples to oxidation was assessed using the FOX method, which consists of an induced method that measures the LHP formed in the FOX reaction media over time $(23,24)$.

Oxidation (TBA values) and susceptibility to oxidation (final LHP values obtained from the FOX assay) decreased in the following order: liver, meat, and plasma (Table 1). This order is consistent with the same decreasing order of fat content in these samples (approximately $4.5 \%$ for liver, $3 \%$ for meat, and $<0.8 \%$ for plasma). The TBA and final LHP values were relatively low compared to those of other animals fed more unsaturated diets $(19,26)$. In fact, plasma TBA was below the detection limit in all samples (13 $\mu \mathrm{g}$ of MDA/L plasma) (Table 1). This finding might be related to plasma high $\alpha \mathrm{T}$ content compared to its fat content.

The addition of PSO to feeds at 3\% (w/w) favored meat susceptibility to oxidation and reduced the $\alpha \mathrm{T}$ content of plasma, liver, and meat (Table 1). Heat treatment of PSO decreased its $\alpha \mathrm{T}$ content, thereby affecting the $\alpha \mathrm{T}$ content of the feed (Table 1). This reduced dietary $\alpha \mathrm{T}$ content would explain both the decreased $\alpha \mathrm{T}$ content found in tissues and their increased susceptibility to oxidation.

In addition, meat from rabbits on the OSO diet also tended to be more susceptible to oxidation than meat from rabbits on the FSO diet, as shown by the IT, MAXLHP, TMAX, and AUC in the FOX assay (Table 1). However, the $\alpha \mathrm{T}$ content of OSO meats was similar to that of FSO meats; thus, the greater susceptibility to oxidation of the former could be attributed to the high content of oxidation compounds in feeds containing OSO oil.

Literature from studies assessing the oxidative stability of tissues from rabbits fed heated oils is lacking. Some studies dealing with chickens fed fresh and heated oils (containing a high amount of primary oxidation compounds) that had a similar $\alpha \mathrm{T}$ content showed a reduced meat $\alpha \mathrm{T}$ content and an increased susceptibility to oxidation $(11,12)$. In previous studies $(19,26)$, we found no significant differences in the $\alpha \mathrm{T}$ content, oxidation (TBA value), and susceptibility to oxidation (LHP value) of raw chicken meat when chickens received feeds containing FSO or SO heated for different times and at distinct temperatures (leading to a high content of either primary or secondary oxidation compounds). However, results obtained by Bou et al. (19) showed a trend similar to those of the present study.

All of these observations indicate that, apart from the lower $\alpha \mathrm{T}$ supply, other mechanisms might contribute to the lower $\alpha \mathrm{T}$ content of plasma, liver, and meat and to the higher susceptibility of liver and meat to oxidation. Indeed, $\alpha \mathrm{T}$ could be lost in the gastrointestinal tract because of its reaction with radical species present in higher amounts in PSO oil than in OSO and FSO oils, thereby reducing the amount of $\alpha \mathrm{T}$ available for absorption (12). Furthermore, in tissues, $\alpha \mathrm{T}$ could be reduced as a result of the promotion of oxidation by some of the oxidation products absorbed (12). Secondary oxidation compounds are absorbed in the gastrointestinal tract $(5,7)$. However, LHP are not likely to be absorbed in their intact form. After previous breakdown of LHP in the stomach and reduction by gluthatione peroxidase in the intestinal epithelium, several compounds containing hydroxyl, epoxy, or keto groups derived from LHP might be absorbed (9). Therefore, the in vivo pro-oxidative effect of the oxidation compounds from the diet is difficult to explain (27).
The $\alpha \mathrm{T}$ contents in our oils and feeds differed, and we were therefore unable to attribute the effects observed on rabbit liver and meat $\alpha \mathrm{T}$ content and susceptibility to oxidation to all or to only some of these factors.

Supplementation with TA can improve meat oxidative stability, shelf life, and overall quality, especially when unsaturated fat sources are added to feed ( 1 ). In our study, dietary supplementation with $100 \mathrm{mg}$ of TA $/ \mathrm{kg}$ reduced liver TBA values and also liver and meat susceptibility to oxidation (FOX method) as a result of the increase in $\alpha \mathrm{T}$ in plasma, liver, and meat (Table 1).

Despite the efficiency of TA supplementation in increasing the $\alpha \mathrm{T}$ content in tissues and decreasing susceptibility to oxidation, significant interactions were found between the type of sunflower oil added to the feed and TA supplementation (Table 2). The higher susceptibility to oxidation of meat from animals on PSO diet than of meat from animals on OSO and FSO diets was evident after TA supplementation. This was reflected by shorter IT and TMAX and higher MAXLHP, AUC, and final LHP of meats from animals on diets with PSO and TA (Table 2). These observations could be explained by the lower $\alpha \mathrm{T}$ content of the TA-PSO feed than the TA-OSO and TA-FSO feeds, together with a greater loss of $\alpha \mathrm{T}$ in the gastrointestinal tract as a result of the presence of a high amount of primary oxidation compounds in PSO feed. In addition, several oxidation compounds could be absorbed from diets $(4,9,12)$, which would also explain why meat from animals on the TA-OSO diet was slightly more susceptible to oxidation than meat from animals on theTA-FSO diet, although the diet had a similar $\alpha$ T content. Thus, our results show that when oxidized oils are added to feed, TA supplementation is required to reduce tissue susceptibility to oxidation. However, this supplementation must be adjusted depending on the degree of oxidation of the oil added.

Increases in meat $\alpha \mathrm{T}$ content with concomitant decreases in meat oxidation (TBA values) or in its susceptibility to oxidation (measured by means of the FOX method as in our study or by the TBA value after the induction of oxidation under standard conditions) have been reported in rabbit and other animal species as a result of the dietary supplementation with TA $(19,22,26,28-31)$. In our study, meat TBA values were low and not significantly reduced by TA supplementation (Table 1). The lower oil content in rabbit feed, the low fat content of rabbit meat compared to meat from other species, and its low content of FA having more than two double bonds [from which MDA is produced (2)] explained why meat oxidation (TBA values) was not high and why TA supplementation did not reduce it even more. However, the $\alpha \mathrm{T}$ contents of plasma, liver, and meat correlated with each other and with the FOX parameters (IT, TMAX, MAXLHP, final LHP, and AUC) of meat (Table 3). This observation supports the notion that the FOX parameters reflected the protective effect of TA supplementation. Therefore, the FOX method is useful to assess the susceptibility to oxidation of meat, especially meat with a low oxidation (TBA values). Correlations also showed that the $\alpha \mathrm{T}$ content of plasma, liver, and rabbit meat was positively correlated between these tissues. This finding indicates that plasma $\alpha \mathrm{T}$ content is a good indicator of $\alpha \mathrm{T}$ content in tissues (Table 3 ) and is consistent with observations reported in rabbit and other species $(11,12,22,30,31)$.

Supplementation with $200 \mathrm{mg}$ of $\mathrm{Zn} / \mathrm{kg}$ of feed did not alter the $\alpha$ T content of rabbit tissues or meat TBA (Table 1), although it slightly decreased meat $\mathrm{Cu}$ content (32), which in some studies has led to decreases in the activities of some antioxidant enzymes, such as copper-zinc superoxide dismutase (33). However, meat TBA values were not affected by $\mathrm{Zn}$ supplementation in previous studies in chickens $(19,21,34)$. 
Table 2. Effect of the Degree of Oxidation of the Oil Added to Feed and Supplementation with $\alpha$-Tocopheryl Acetate ( 0 or $100 \mathrm{mg} / \mathrm{kg}$ of Feed) on $\alpha$-Tocopherol Content and FOX Values of Rabbit Plasma, Liver, and Meat ${ }^{a, b}$

\begin{tabular}{|c|c|c|c|c|c|c|c|}
\hline & \multirow[b]{2}{*}{$P$} & \multicolumn{3}{|c|}{$0 \mathrm{mg}$ of $\mathrm{TA} / \mathrm{kg}$} & \multicolumn{3}{|c|}{$100 \mathrm{mg}$ of $\mathrm{TA} / \mathrm{kg}$} \\
\hline & & FSO & PSO & Oso & FSO & PSO & OSO \\
\hline \multicolumn{8}{|l|}{ feed } \\
\hline $\begin{array}{l}\alpha \mathrm{T} \text { content ( } \mathrm{mg} \text { of } \alpha \mathrm{T} / \mathrm{kg} \text { of feed) } \\
\text { plasma }\end{array}$ & \multicolumn{6}{|c|}{ plasma } & 115.9 \\
\hline$\alpha \mathrm{T}$ content (mg of $\alpha \mathrm{T} / \mathrm{L}$ of plasma) & 0.056 & 2.82 & 1.77 & 2.61 & 5.60 & 5.40 & 5.43 \\
\hline final LHP (mmol of CHP equiv/L of plasma) & 0.233 & 0.044 & 0.052 & 0.045 & 0.043 & 0.044 & 0.045 \\
\hline \multicolumn{8}{|l|}{ liver } \\
\hline$\alpha \mathrm{T}$ content ( $\mathrm{mg}$ of $\alpha \mathrm{T} / \mathrm{kg}$ of liver) & 0.683 & 5.65 & 3.23 & 4.82 & 14.6 & 12.7 & 13.0 \\
\hline final LHP (mmol of CHP equiv/kg of liver) & 0.672 & 8.66 & 10.32 & 8.72 & 2.77 & 2.87 & 2.48 \\
\hline \multicolumn{8}{|l|}{ raw meat } \\
\hline$\alpha T$ content ( $\mathrm{mg}$ of $\alpha \mathrm{T} / \mathrm{kg}$ of meat) & 0.847 & 1.49 & 0.90 & 1.49 & 4.26 & 3.55 & 4.07 \\
\hline IT (h) & 0.000 & 21 & 0.5 & 9 & $216^{c}$ & 75 & $168^{c}$ \\
\hline MAXLHP (mmol of CHP equiv/kg of meat) & 0.000 & 0.74 & 0.88 & 0.86 & 0.08 & 0.53 & 0.22 \\
\hline TMAX (h) & 0.013 & 72 & 45 & 57 & $216^{c}$ & 147 & $201^{c}$ \\
\hline final LHP (mmol CHP eq/kg meat) & 0.000 & 0.50 & 0.58 & 0.61 & 0.08 & 0.46 & 0.21 \\
\hline AUC $[(\mathrm{mmol}$ of $\mathrm{CHP}$ equiv $/ \mathrm{kg}$ of meat $) \times \mathrm{h}]$ & 0.057 & 111 & 141 & 138 & 13 & 62 & 24 \\
\hline \multicolumn{8}{|l|}{ cooked meat } \\
\hline$\alpha T$ content ( $\mathrm{mg}$ of $\alpha \mathrm{T} / \mathrm{kg}$ of meat) & 0.520 & 1.59 & 0.86 & 1.56 & 4.19 & 3.61 & 3.98 \\
\hline IT (h) & 0.000 & 27 & 0.5 & 21 & $216^{c}$ & $129^{c}$ & $207^{c}$ \\
\hline MAXLHP (mmol of CHP equiv/ $/ \mathrm{kg}$ of meat) & 0.222 & 0.79 & 0.92 & 0.81 & 0.10 & 0.38 & 0.14 \\
\hline $\operatorname{TMAX}(\mathrm{h})$ & 0.602 & 54 & 45 & 54 & $216^{c}$ & $213^{c}$ & $216^{c}$ \\
\hline final LHP (mmol of CHP equiv $/ \mathrm{kg}$ of meat) & 0.013 & 0.59 & 0.63 & 0.60 & 0.10 & 0.38 & 0.14 \\
\hline $\begin{array}{l}\text { AUC }[(\mathrm{mmol} \text { of } \mathrm{CHP} \text { equiv } / \mathrm{kg} \text { of meat }) \times \mathrm{h}] \\
\text { refrigerated cooked meat }\end{array}$ & 0.718 & 119 & 145 & 126 & 14 & 31 & 13 \\
\hline$\alpha T$ content (mg of $\alpha \mathrm{T} / \mathrm{kg}$ of meat) & 0.669 & 1.51 & 0.81 & 1.48 & 4.09 & 3.33 & 3.81 \\
\hline IT (h) & 0.010 & 24 & 0.5 & 18 & $216^{c}$ & 123 & $201^{c}$ \\
\hline MAXLHP (mmol of CHP equiv/ $/ \mathrm{kg}$ of meat) & 0.974 & 0.69 & 0.94 & 0.74 & 0.07 & 0.32 & 0.11 \\
\hline TMAX (h) & 0.222 & 60 & 48 & 60 & $216^{c}$ & 171 & $209^{c}$ \\
\hline final LHP (mmol of CHP equiv $/ \mathrm{kg}$ of meat) & 0.922 & 0.45 & 0.68 & 0.48 & 0.06 & 0.27 & 0.10 \\
\hline AUC $[(\mathrm{mmol}$ of $\mathrm{CHP}$ equiv/kg of meat $) \times \mathrm{h}]$ & 0.099 & 98 & 152 & 108 & 11 & 38 & 15 \\
\hline
\end{tabular}

${ }^{a}$ Abbreviations: TA, $\alpha$-tocopheryl acetate; FSO, fresh sunflower oil; PSO, peroxidized sunflower oil; OSO, oxidized sunflower oil; $\alpha \mathrm{T}, \alpha$-tocopherol; LHP, lipid hydroperoxide; IT, induction time; MAXLHP, maximum LHP value; TMAX, time to reach the MAXLHP value; AUC, area under the curve. ${ }^{b}$ Values given are least-squares means obtained from multifactor ANOVA for the interactions $(n=48)$. ${ }^{C}$ If oxidation had not increased in the samples by the end of reaction time, the final time (216 $\mathrm{h}$ ) was considered to be the TMAX for these samples. Therefore, some values could be underestimated.

Table 3. Pearson Correlation Coefficients between the $\alpha$-Tocopherol Content, Oxidation (TBA Value), and Susceptibility to Oxidation (FOX Values) of Rabbit Plasma $(n=48)$, Liver $(n=48)$, and Meat $(n=48)^{a}$

\begin{tabular}{|c|c|c|c|c|c|c|c|c|c|c|c|c|}
\hline & \multirow[b]{2}{*}{$\alpha \top$ plasma } & \multirow[b]{2}{*}{$\alpha \mathrm{T}$ liver } & \multirow[b]{2}{*}{$\alpha T$ meat } & \multirow[b]{2}{*}{ TBA liver } & \multirow[b]{2}{*}{ TBA meat } & \multirow[b]{2}{*}{ final LHP plasma } & \multirow[b]{2}{*}{ final LHP liver } & \multicolumn{5}{|c|}{ FOX values meat } \\
\hline & & & & & & & & IT & MAXLHP & TMAX & final LHP & AUC \\
\hline$\alpha \top$ plasma & 1 & $0.899^{* *}$ & $0.953^{\star \star}$ & $-0.448^{* *}$ & -0.149 & $-0.307^{\star}$ & 0.022 & $0.802^{* *}$ & $-0.816^{\star *}$ & $0.865^{\star \star}$ & $-0.722^{* *}$ & $-0.857^{\star *}$ \\
\hline$\alpha \mathrm{T}$ liver & & 1 & $0.916^{\star \star}$ & -0.226 & $-0.280^{*}$ & $-0.292^{*}$ & -0.104 & $0.810^{\star *}$ & $-0.830^{\star \star}$ & $0.849^{\star \star}$ & $-0.750^{\star *}$ & $-0.853^{\star \star}$ \\
\hline$\alpha \mathrm{T}$ meat & & & 1 & $-0.322^{*}$ & -0.211 & $-0.311^{*}$ & -0.003 & $0.878^{* *}$ & $-0.875^{\star *}$ & $0.896^{* *}$ & $-0.803^{\star *}$ & $-0.887^{\star *}$ \\
\hline TBA liver & & & & 1 & -0.075 & -0.153 & -0.233 & -0.216 & 0.184 & -0.260 & 0.125 & 0.228 \\
\hline TBA meat & & & & & 1 & 0.165 & -0.072 & -0.059 & 0.120 & -0.032 & 0.098 & 0.125 \\
\hline final LHP plasma & & & & & & 1 & -0.047 & -0.221 & $0.312^{*}$ & -0.229 & 0.265 & $0.319^{*}$ \\
\hline final LHP liver & & & & & & & 1 & -0.031 & -0.041 & -0.059 & -0.047 & -0.071 \\
\hline \multicolumn{13}{|l|}{ FOX values meat } \\
\hline IT & & & & & & & & 1 & $-0.952^{\star *}$ & $0.934^{* \star}$ & $-0.938^{* *}$ & $-0.911^{\star *}$ \\
\hline MAXLHP & & & & & & & & & 1 & $-0.923^{\star \star}$ & $0.977^{\star *}$ & $0.984^{* *}$ \\
\hline TMAX & & & & & & & & & & 1 & $-0.850^{\star *}$ & $-0.934^{* *}$ \\
\hline final LHP & & & & & & & & & & & 1 & $0.933^{\star *}$ \\
\hline AUC & & & & & & & & & & & & 1 \\
\hline
\end{tabular}

${ }^{a}$ Abbreviations: TBA, thiobarbituric acid; FOX, ferrous oxidation-xylenol orange; $\alpha$ T, $\alpha$-tocopherol content; IT, induction time; MAXLHP, maximum LHP value; TMAX, time to reach the MAXLHP; AUC, area under the curve. ${ }^{*}, P$ value $\leq 0.05 ;{ }^{* *}, P$ value $\leq 0.001$.

Zn supplementation, however, altered meat susceptibility to oxidation depending on the degree of oxidation of oils added to feeds (Table 4). This was consistent with an interaction observed between these two factors for the FA content of meats (Table 4) (32). Meat susceptibility to oxidation depends on the balance between antioxidants, pro-oxidants, and substrates (10). Zn supplementation did not modify the $\alpha \mathrm{T}$ content of meat from animals on OSO feed, but led to a slight increase in its FA content
(Table 4) (32) and, thus, in its susceptibility to oxidation, as indicated by the shorter IT and TMAX and higher MAXLHP, final LHP, and AUC (Table 4). Conversely, Zn supplementation in feed containing PSO led to a slight decrease in meat FA content (32) and thus in meat susceptibility to oxidation (Table 4). $\mathrm{Zn}$ supplementation did not alter the susceptibility to oxidation of meat from animals on the FSO diet. Plasma and liver FA composition was not altered by this interaction, and thus neither 
Table 4. Effect of the Degree of Oxidation of the Oil Added to Feeds and the Supplementation with Zinc ( 0 or $200 \mathrm{mg} / \mathrm{kg}$ of Feed) on the Fatty Acid Composition, $\alpha$-Tocopherol Content, and Susceptibility to Oxidation of Raw Rabbit Meat ${ }^{a, b}$

\begin{tabular}{|c|c|c|c|c|c|c|c|}
\hline & \multirow[b]{2}{*}{$P$} & \multicolumn{2}{|c|}{ FSO } & \multicolumn{2}{|c|}{ PSO } & \multicolumn{2}{|c|}{ OSO } \\
\hline & & $0 \mathrm{Zn}$ & $200 \mathrm{Zn}$ & $0 \mathrm{Zn}$ & $200 \mathrm{Zn}$ & $0 \mathrm{Zn}$ & $200 \mathrm{Zn}$ \\
\hline \multicolumn{8}{|l|}{ fatty acid composition (mg of FA/100 g of meat) } \\
\hline SFA & 0.008 & 830 & 750 & 880 & 780 & 720 & 860 \\
\hline MUFA & 0.032 & 580 & 530 & 600 & 530 & 510 & 590 \\
\hline n-6 PUFA & 0.016 & 1120 & 1050 & 1180 & 1090 & 990 & 1130 \\
\hline n-3 PUFA & 0.009 & 58 & 54 & 65 & 58 & 54 & 62 \\
\hline total PUFA & 0.016 & 1180 & 1100 & 1240 & 1150 & 1050 & 1190 \\
\hline total trans FA & 0.017 & 14.3 & 12.2 & 14.0 & 12.7 & 12.3 & 13.6 \\
\hline $\begin{array}{l}\alpha \mathrm{T} \text { content (mg of } \alpha \mathrm{T} / \mathrm{kg} \text { of meat) } \\
\text { susceptibility to oxidation (FOX values) }\end{array}$ & 0.328 & susceptibility to oxidation (FOX values) & 2.70 & 2.22 & 2.23 & 2.72 & 2.84 \\
\hline IT (h) & 0.003 & $120^{c}$ & $117^{\mathrm{c}}$ & 30 & 45 & $114^{c}$ & $63^{c}$ \\
\hline MAXLHP (mmol of CHP equiv/kg of meat) & 0.001 & 0.41 & 0.42 & 0.78 & 0.63 & 0.46 & 0.65 \\
\hline $\operatorname{TMAX}(\mathrm{h})$ & 0.000 & $147^{c}$ & $141^{c}$ & 72 & 120 & $138^{c}$ & $120^{c}$ \\
\hline final LHP ( $\mathrm{mmol}$ of CHP equiv $/ \mathrm{kg}$ of meat) & 0.000 & 0.29 & 0.29 & 0.56 & 0.47 & 0.33 & 0.49 \\
\hline AUC $[(\mathrm{mmol}$ of CHP equiv $/ \mathrm{kg}$ of meat $) \times \mathrm{h}]$ & 0.001 & 62 & 63 & 117 & 86 & 69 & 93 \\
\hline
\end{tabular}

${ }^{a}$ Abbreviations: FSO, fresh sunflower oil; PSO, peroxidized sunflower oil; OSO, oxidized sunflower oil; FA, fatty acids; SFA, saturated fatty acids; MUFA, monounsaturated fatty acids; PUFA, polyunsaturated fatty acids; $\alpha$ T, $\alpha$-tocopherol; FOX, ferrous oxidation-xylenol orange; IT, induction time; MAXLHP, maximum lipid hydroperoxide value; $\mathrm{CHP}$, cumene hydroperoxide; TMAX, time to reach the MAXLHP value; AUC, area under the curve. ${ }^{b}$ Values given are least-squares means for the interactions obtained from multifactor ANOVA $(n=48)$. Interaction between oil added to feeds and $\mathrm{Zn}$ supplementation significant at $P \leq 0.05 .{ }^{\circ}$ If oxidation had not increased in samples by the end of the FOX reaction time, the final time $(216 \mathrm{~h})$ was considered the TMAX for these samples. Therefore, some values could be underestimated.

Table 5. Effect of Cooking Meat and Its Subsequent Refrigeration on Meat $\alpha$-Tocopherol Content, Oxidation (TBA Value), and Oxidative Stability (FOX Values) ${ }^{a}$

\begin{tabular}{llll}
\hline & raw meat & cooked meat & refrigerated cooked meat \\
\hline $\begin{array}{l}\alpha \text {-tocopherol content (mg of } \alpha \mathrm{T} / \mathrm{kg} \text { of meat) } \\
\text { oxidation }\end{array}$ & 2.63 & 2.63 & 2.51 \\
$\quad$ TBA value ( $\mu \mathrm{g}$ of MDA $/ \mathrm{kg}$ of meat) & $23 \mathrm{x}$ & $29 \mathrm{y}$ & $783 \mathrm{z}$ \\
$\begin{array}{l}\text { susceptibility to oxidation } \\
\text { IT }(\mathrm{h})\end{array}$ & $81.7 \mathrm{x}$ & $100.1 \mathrm{y}$ & $97 \mathrm{y}$ \\
MAXLHP (mmol of CHP equiv/kg of meat) & 0.56 & 0.52 & 0.48 \\
TMAX (h) & $123 \mathrm{x}$ & $133 \mathrm{y}$ & $128 \mathrm{y}$ \\
final LHP (mmol of CHP equiv/kg of meat) & $0.41 \mathrm{y}$ & $0.41 \mathrm{y}$ & $0.34 \mathrm{x}$ \\
AUC [(mmol of CHP equiv/kg of meat) $\times \mathrm{h}]$ & $82 \mathrm{y}$ & $74 \mathrm{x}$ & $70 \mathrm{x}$ \\
\hline
\end{tabular}

a Abbreviations: TBA, thiobarbituric acid; FOX, ferrous oxidation-xylenol orange; $\alpha$ T, $\alpha$-tocopherol; MDA, malondialdehyde; LHP, lipid hydroperoxide; IT, induction time; MAXLHP, maximum LHP value; TMAX, time to reach the maximum LHP value; AUC, area under the curve. Values in the same row bearing no common letters ( $x-z)$ are statistically different $(P \leq 0.05)$. Letters were obtained by means of Scheffé test $(\alpha=0.05)$. Values correspond to least-squares means obtained from multifactor ANOVA (raw meat vs cooked meat, $n=96$; cooked meat vs refrigerated cooked meat, $n=96$ ).

was their susceptibility to oxidation. More research is needed to ascertain why Zn supplementation altered rabbit meat FA content depending on the oxidation status of the oil added to feeds (32).

Furthermore, an effect of the interaction between dietary supplementation with TA and $\mathrm{Zn}$ was observed for liver TBA values. The highest TBA values were found in liver from animals that did not receive TA or $\mathrm{Zn}$ supplementation [67 $\mu \mathrm{g}$ of MDA $/ \mathrm{kg}$ for liver from $0 \mathrm{TA}-0 \mathrm{Zn}$ diets vs 61,59 , and $53 \mu \mathrm{g}$ of $\mathrm{MDA} / \mathrm{kg}$ for $0 \mathrm{TA}-200 \mathrm{Zn}, 100 \mathrm{TA}-200 \mathrm{Zn}$, and $100 \mathrm{TA}-0 \mathrm{Zn}$ diets, respectively (SEM, $2.9 \mu \mathrm{g}$ of MDA/ $\mathrm{kg}$ )]. The lowest TBA values were detected when $100 \mathrm{mg}$ of TA/ $\mathrm{kg}$ of feed was added without $\mathrm{Zn}$ supplementation; thus, it seems that $\mathrm{Zn}$ supplementation diminished somehow the protective effect of TA supplementation against oxidation in liver.

Effect of Cooking and Refrigeration of Cooked Meat on the Oxidation and Oxidative Stability of Meat. The cooking and storage of raw and cooked meat have been reported to affect meat oxidation $(10,26,28,29)$, but the values reached depend on the cooking and storage conditions $(35,36)$. The effects of cooking on meat oxidation have been related to protein denaturation (loss of antioxidant enzyme activity and release of prooxidant metal ions such as nonheme iron), myoglobin oxidation, or the disruption of cell membranes, which might bring PUFA into contact with pro-oxidant compounds $(10,26)$. These factors, together with the time, temperature, and cooking conditions used (35), might promote meat oxidation.

In our study, cooking conditions were mild (vacuum-packed meat, at $80^{\circ} \mathrm{C}$, for $5 \mathrm{~min}$ ), thus leading to a slight increase in meat TBA value after cooking. However, during refrigerated storage $\left(5{ }^{\circ} \mathrm{C}, 62\right.$ days $)$ of cooked meat, the TBA value increased (Table 5), although these values were not as high as those reported in other studies $(26,37)$. Furthermore, we did not find differences in meat $\alpha \mathrm{T}$ content after cooking or after the refrigerated storage of cooked meat (Table 5).

Although it was expected that the changes in meat induced by cooking might increase its susceptibility to oxidation, results from the FOX method showed that it slightly decreased (Table 5). However, the comparison between raw and cooked samples should be made with care. The FOX method is an induced method that measures the formation of LHP in a methanolic extract of the sample. In general, it is advisable to compare samples (methanolic extracts) with similar characteristics when this type of method is used (23). Given that the composition of the methanolic extract might differ slightly between raw and cooked samples, the development of the FOX reaction might be affected and, thus, the FOX values and parameters obtained. This would explain the changes in meat susceptibility to oxidation after cooking. However, as shown by the Pearson's correlation coefficients (Table 6), the susceptibility of raw meat to oxidation, as measured by the FOX 
Table 6. Pearson Correlation Coefficients between Raw Meat $\alpha$-Tocopherol Content and TBA and FOX Values of Raw ( $n=48)$, Cooked ( $n=48)$, and Refrigerated Cooked Meat $(n=48)^{a}$

\begin{tabular}{|c|c|c|c|c|c|c|c|c|c|c|c|c|c|c|c|c|}
\hline & & & & & & FOX val & lues RM & & & FOX va & alues CM & & & FOX val & Iues RCM & \\
\hline & $\alpha \mathrm{T}$ RM & И TBA RM & TBA CM & TBA RCM & IT & TMAX & final LHP & AUC & IT & TMAX & final LHP & AUC & IT & TMAX & final LHP & AUC \\
\hline$\alpha \mathrm{T}$ RM & 1 & -0.211 & $-0.614^{\star \star}$ & -0.179 & $0.878^{\star \star}$ & $0.896^{\star \star}$ & $-0.803^{* *}$ & $-0.887^{* \star}$ & $0.918^{\star *}$ & $0.935^{\star \star}$ & $-0.840^{\star *}$ & $-0.913^{\star *}$ & $0.887^{\star \star}$ & $0.904^{* *}$ & ${ }^{*}-0.849^{\star *}$ & $-0.901^{\star \star}$ \\
\hline TBA RM & & 1 & 0.109 & $0.295^{*}$ & -0.059 & -0.032 & 0.098 & 0.125 & -0.190 & -0.257 & 0.259 & 0.267 & -0.148 & -0.171 & 0.043 & 0.113 \\
\hline TBA CM & & & 1 & -0.085 & $-0.522^{\star *}$ & $-0.553^{\star \star}$ & $0.440^{\star *}$ & $0.539^{\star *}$ & $-0.603^{\star *}$ & $-0.580^{\star *}$ & $0.542^{* *}$ & $0.598^{\star *}$ & $-0.531^{\star \star}$ & $-0.586^{\star *}$ & * $\quad 0.542^{\star *}$ & $0.589^{* \star}$ \\
\hline TBA RCM & & & & 1 & -0.052 & -0.039 & 0.083 & 0.050 & -0.142 & -0.115 & 0.053 & 0.016 & -0.212 & -0.152 & 0.186 & 0.153 \\
\hline FOX values & & & & & & & & & & & & & & & & \\
\hline IT & & & & & 1 & $0.934^{\star *}$ & $-0.938^{\star \star}$ & $-0.911^{\star \star}$ & $0.811^{\star \star}$ & $0.818^{\star \star}$ & $-0.819^{\star \star}$ & $-0.824^{\star \star}$ & $0.868^{\star \star}$ & $0.846^{* \star}$ & ${ }^{\star}-0.828^{\star \star}$ & $-0.832^{\star \star}$ \\
\hline TMAX & & & & & & 1 & $-0.850^{\star *}$ & $-0.934^{\star \star}$ & $0.884^{* *}$ & $0.882^{* *}$ & $-0.797^{\star \star}$ & $-0.869^{\star \star}$ & $0.922^{* *}$ & $0.907^{\star *}$ & * $-0.879^{* *}$ & $-0.895^{\star \star}$ \\
\hline final LHP & & & & & & & 1 & $0.933^{\star *}$ & $-0.814^{\star \star}$ & $-0.742^{* *}$ & $0.760^{\star *}$ & $0.734^{* *}$ & $-0.807^{\star *}$ & $-0.786^{\star *}$ & * $\quad 0.763^{\star *}$ & $0.776^{\star \star}$ \\
\hline AUC & & & & & & & & 1 & $-0.872^{\star *}$ & $-0.877^{\star *}$ & $0.792^{\star *}$ & $0.854^{\star *}$ & $-0.885^{\star *}$ & $-0.889^{\star *}$ & * $\quad 0.845^{\star *}$ & $-0.911^{\star \star}$ \\
\hline FOX values & & & & & & & & & & & & & & & & \\
\hline IT & & & & & & & & & 1 & $0.929^{* *}$ & $-0.895^{\star *}$ & $-0.929^{\star *}$ & $0.912^{* *}$ & $0.928^{\star *}$ & ${ }^{*}-0.874^{\star *}$ & $-0.911^{\star \star}$ \\
\hline TMAX & & & & & & & & & & 1 & $-0.811^{* *}$ & $-0.947^{\star *}$ & $0.872^{* \star}$ & $0.923^{* *}$ & ${ }^{*}-0.818^{\star \star}$ & $-0.903^{\star \star}$ \\
\hline final LHP & & & & & & & & & & & 1 & $0.788^{* *}$ & $-0.856^{\star *}$ & $-0.864^{\star *}$ & * $\quad 0.747^{\star *}$ & $0.784^{\star \star}$ \\
\hline AUC & & & & & & & & & & & & 1 & $-0.876^{\star *}$ & $-0.912^{\star *}$ & * $\quad 0.805^{\star *}$ & $0.883^{\star \star}$ \\
\hline FOX values & & & & & & & & & & & & & & & & \\
\hline IT & & & & & & & & & & & & & 1 & $0.963^{* \star}$ & ${ }^{\star}-0.912^{\star *}$ & $-0.915^{\star \star}$ \\
\hline TMAX & & & & & & & & & & & & & & 1 & $-0.890^{\star *}$ & $-0.932^{\star \star}$ \\
\hline final LHP & & & & & & & & & & & & & & & 1 & $0.970^{\star \star}$ \\
\hline AUC & & & & & & & & & & & & & & & & 1 \\
\hline
\end{tabular}

${ }^{a}$ Abbreviations: RM, raw meat; CM, cooked meat; RCM, refrigerated cooked meat, $\alpha \mathrm{T}, \alpha$-tocopherol content; TBA, thiobarbituric acid; FOX, ferrous oxidation-xylenol orange; LHP, lipid hydroperoxide; IT, induction time; TMAX, time to reach the maximum LHP value; AUC, area under the curve. ${ }^{*}, P$ value $\leq 0.05 ;{ }^{* *}, P$ value $\leq 0.001$.

method, is a useful predictor of meat oxidation (TBA value) after cooking.

During the refrigeration of cooked meat, the low oxygen availability and refrigeration temperature may have slowed the formation of new LHP, which may have been decomposed more quickly into secondary oxidation products, such as MDA, thus leading to an increase in TBA value and to similar FOX parameters (Table 6).

Dietary supplementation with $100 \mathrm{mg}$ of $\mathrm{TA} / \mathrm{kg}$ of feed increased the $\alpha \mathrm{T}$ content of cooked and refrigerated cooked meat, as it did in raw meat (Table 1). This led to reductions of meat susceptibility to oxidation (reflected by all of the parameters from the FOX method) both after cooking and after the refrigeration of cooked meat (Table 1). TA supplementation also led to a $35 \%$ reduction in meat TBA after cooking. However, given the high variability among samples, no significant differences were found after refrigeration (Table 1). Thus, the $\alpha \mathrm{T}$ contents of all raw, cooked, and refrigerated cooked meat were strongly correlated with the parameters that measure the susceptibility of meat to oxidation after cooking and subsequent refrigeration (Table 6).

The lower $\alpha \mathrm{T}$ content in raw meat as a result of the addition of PSO oils to feed was still significant in cooked and in refrigerated cooked meat (Table 1). Similarly to raw meat, TBA content did not differ, but meat susceptibility to oxidation increased with the addition of this oil, as shown by the FOX parameters (Table 1). In some studies with chickens $(29,38)$, differences in meat oxidation after cooking or after storage were found as a result of administering diets containing oxidized oils (high in primary oxidation compounds). However, the $\alpha \mathrm{T}$ content of those oils had been reduced during heating, thereby leading to a lower meat $\alpha \mathrm{T}$ content $(29,38)$. In other studies, in which $\alpha \mathrm{T}$ losses in oil caused by heating were corrected, heated oils did not modify the oxidation (TBA values) of cooked chicken meat or the susceptibility of this meat to oxidation (Final LHP values) (19). Similar results were found by Grau et al. (26), although they did not correct $\alpha \mathrm{T}$ losses in heated SO oil. They attributed this lack of a significant effect to the low LHP content of their heated oil tested.

Dietary supplementation with $\mathrm{Zn}(200 \mathrm{mg} / \mathrm{kg})$ did not affect the TBA content of refrigerated cooked meat; however, it slightly increased this parameter in cooked meat. The same tendency, although not significant, was observed in raw meat, whereas the opposite trend was detected in refrigerated cooked meat (Table 1). In previous studies, no differences in the TBA value were observed after cooking and after storage of meat from chickens fed diets supplemented with $\mathrm{Zn}(19,21)$.

In summary, the presence of a high content of primary and secondary oxidation compounds in fats added to feeds increased meat susceptibility to oxidation. The highest increase was observed when PSO oil was used in feeds, which reduced the $\alpha \mathrm{T}$ content of rabbit plasma, liver, and meat, facts that could be related to the lower $\alpha \mathrm{T}$ supply from feeds when this oil was used. However, other mechanisms might also be involved. Dietary supplementation with TA reduced meat and liver susceptibility to oxidation; however, this supplementation must be adjusted depending on the oxidation of the fat added to feeds. The dietary supplementation with $\mathrm{Zn}$ slightly decreased the susceptibility to oxidation of meat from rabbit on PSO diets and increased that of meat from rabbits on OSO diets. These effects of $\mathrm{Zn}$ supplementation were according to alterations of meat FA content; however, more research is needed to discern the mechanisms that led to such alterations. The FOX method was useful to assess raw meat susceptibility to oxidation, which in turn was a good predictor of meat oxidation after cooking.

\section{ACKNOWLEDGMENT}

We thank Frit Ravich and Laboratorios Salvat for use of their facilities for heating the experimental oils. We also thank the Department of Animal Science at the Polytechnic University of Valencia for housing the animals and for slaughtering facilities and E. Carmona, M. Redecker, and M. Gonzalo for their help in the analyses.

\section{LITERATURE CITED}

(1) Bou, R.; Codony, R.; Tres, A.; Guardiola, F.; Decker, E. A. Dietary strategies to improve nutritional value, oxidative stability and sensory properties of poultry products. Crit. Rev. Food Sci. Technol. 2009, 49, 800-822.

(2) Frankel, E. N. Lipid Oxidation; Oily Press: Dundee, U.K., 1998.

(3) Nuchi, C. D.; Guardiola, F.; Bou, R.; Bondioli, P.; Della Bella, L.; Codony, R. Assessment of the levels of degradation in fat co- and 
byproducts for feed uses and their relationship with some lipid composition parameters. J. Agric. Food Chem. 2009, 57, 1952-1959.

(4) Billek, G. Health aspects of thermoxidized oils and fats. Eur. J. Lipid Sci. Technol. 2000, 102, 587-593.

(5) Marquez-Ruiz, G.; Garcia-Martinez, M. C.; Holgado, F. Changes and effects of dietary oxidized lipids in the gastrointestinal tract. Lipid Insights 2008, 2, 11-19.

(6) Esterbauer, H. Cytotoxicity and genotoxicity of lipid-oxidation products. Am. J. Clin. Nutr. 1993, 57, S779-S786.

(7) Guardiola, F.; Dutta, P. C.; Codony, R.; Savage, G. P. Cholesterol and Phytosterol Oxidation Products: Analysis, Ocurrence, And Biological Effects; AOCS Press: Champaign, IL, 2002.

(8) Spiteller, G. Peroxyl radicals: Inductors of neurodegenerative and other inflammatory diseases. Their origin and how they transform cholesterol, phospholipids, plasmalogens, polyunsaturated fatty acids, sugars, and proteins into deleterious products. Free Radical Biol. Med. 2006, 41, 362-387.

(9) Kanazawa, K.; Ashida, H. Dietary hydroperoxides of linoleic acid decompose to aldehydes in stomach before being absorbed into the body. Biochim. Biophys. Acta 1998, 1393, 349-361.

(10) Erickson, M. C. Lipid oxidation of muscle foods. In Food Lipids: Chemistry, Nutrition and Biotechnology; Akoh, C. C., Min, D. B., Eds.; CRC Press: Boca Raton, FL, 2007.

(11) Sheehy, P. J. A.; Morrissey, P. A.; Flynn, A. Influence of heated vegetable oils and $\alpha$-tocopheryl acetate supplementation on $\alpha$ tocopherol, fatty acids and lipid peroxidation in chicken muscle. Br. Poult. Sci. 1993, 34, 367-381.

(12) Sheehy, P. J. A.; Morrissey, P. A.; Flynn, A. Consumption of thermally-oxidized sunflower oil by chicks reduces $\alpha$-tocopherol status and increases susceptibility of tissues to lipid oxidation. $B r . J$. Nutr. 1994, 71, 53-65.

(13) European Commission List of the authorized additives in feedingstuffs published in application of Article 9t (b) of Council Directive 70/524/EEC concerning additives in feedingstuffs. Off. J. Eur. Union 2004, $C 50 / 1$.

(14) Deutsche Gesellschaft für Fettwissenschaft (DGF) DGF method C-VI 6a, 2002.

(15) Navas, J. A.; Tres, A.; Codony, R.; Boatella, J.; Bou, R.; Guardiola, F. Modified ferrous oxidation-xylenol orange method to determine lipid hydroperoxides in fried snacks. Eur. J. Lipid Sci. Technol. 2004, 106, 688-696.

(16) AOCS. Official Methods and Recommended Practices of the American Oil Chemists' Society; AOCS Press: Champaign, IL, 1998-2008.

(17) Deutsche Gesellschaft für Fettwissenschaft (DGF) DGF Method C-III 3d, 2000.

(18) IUPAC. Standard method 2508. In IUPAC Standard Methods for the Analysis of Oils, Fats and Derivatives, 1st supplement to the 7th ed.; Blackwell Science: Oxford, U.K., 1992.

(19) Bou, R.; Codony, R.; Baucells, M. D.; Guardiola, F. Effect of heated sunflower oil and dietary supplements on the composition, oxidative stability, and sensory quality of dark chicken meat. J. Agric. Food Chem. 2005, 53, 7792-7801.

(20) Firestone, D. Regulatory requirements for the frying industry. In Frying Technology and Practices; Gupta, M. K., Warner, K., White, P. J., Eds.; AOCS Press: Champaign, IL, 2004.

(21) Bou, R.; Guardiola, F.; Tres, A.; Barroeta, A. C.; Codony, R. Effect of dietary fish oil, $\alpha$-tocopheryl acetate, and zinc supplementation on the composition and consumer acceptability of chicken meat. Poult. Sci. 2004, 83, 282-292.

(22) Tres, A.; Bou, R.; Codony, R.; Guardiola, F. Dietary n-6- or n-3-rich vegetable fats and antioxidants: effects on fatty acid composition and stability of plasma, liver and meat. Animal 2009, 3, 1408-1419.

(23) Bou, R.; Codony, R.; Tres, A.; Decker, E. A.; Guardiola, F. Determination of hydroperoxides in foods and biological samples by the ferrous oxidation-xylenol orange method: a review of the factors that influence the method's performance. Anal. Biochem. 2008, 377, 1-15.

(24) Tres, A.; Nuchi, C. D.; Bou, R.; Codony, R.; Guardiola, F. Assessing rabbit and chicken tissue susceptibility to oxidation through the ferrous oxidation-xylenol orange method. Eur. J. Lipid Sci. Technol. 2009, 111, 563-573.

(25) Grau, A.; Guardiola, F.; Boatella, J.; Barroeta, A. C.; Codony, R. Measurement of 2-thiobarbituric acid values in dark chicken meat through derivative spectrophotometry: influence of various parameters. J. Agric. Food Chem. 2000, 48, 1155-1159.

(26) Grau, A.; Guardiola, F.; Grimpa, S.; Barroeta, A. C.; Codony, R. Oxidative stability of dark chicken meat through frozen storage: influence of dietary fat and alpha-tocopherol and ascorbic acid supplementation. Poult. Sci. 2001, 80, 1630-1642.

(27) Penumetcha, M.; Khan, N.; Parthasarathy, S. Dietary oxidized fatty acids: an atherogenic risk? J. Lipid Res. 2000, 41, 1473-1480.

(28) Tres, A.; Bou, R.; Codony, C.; Guardiola, F. Influence of different dietary doses of $n$-3- or $n$-6-rich vegetable fats and $\alpha$-tocopheryl acetate supplementation on raw and cooked rabbit meat composition and oxidative stability. J. Agric. Food Chem. 2008, 56, 72437253.

(29) Galvin, K.; Morrissey, P.; Buckley, D. J. Influence of dietary vitamin $\mathrm{E}$ and oxidised sunflower oil on the storage stability of cooked chicken muscle. Br. Poult. Sci. 1997, 38, 499-504.

(30) Castellini, C.; Dal Bosco, A.; Bernardini, M. Improvement of lipid stability of rabbit meat by vitamin $\mathrm{E}$ and $\mathrm{C}$ administration. $J$. Sci. Food Agric. 2001, 81, 46-53.

(31) Lo Fiego, D. P.; Santoro, P.; Macchioni, P.; Mazzoni, D.; Piattoni, F.; Tassone, F.; De Leonibus, E. The effect of dietary supplementation of vitamins $\mathrm{C}$ and $\mathrm{E}$ on the $\alpha$-tocopherol content of muscles, liver and kidney, on the stability of lipids, and on certain meat quality parameters of the longissimus dorsi of rabbits. Meat Sci. 2004, 67, 319-327.

(32) Tres, A.; Bou, R.; Codony, R.; Guardiola, F. Oxidized oils and dietary zinc and $\alpha$-tocopheryl acetate supplementation: effects on rabbit plasma, liver and meat fatty acid composition and meat $\mathrm{Zn}$, $\mathrm{Cu}, \mathrm{Fe}$ and $\mathrm{Se}$ content. Animal 2010, doi:10.1017/S1751731110000935

(33) Sundaresan, P. R.; Kaup, S. M.; Wiesenfeld, P. W.; Chirtel, S. J.; Hight, S. C.; Rader, J. I. Interactions in indices of vitamin A, zinc and copper status when these nutrients are fed to rats at adequate and increased levels. Br. J. Nutr. 1996, 75, 915-928.

(34) Bou, R.; Guardiola, F.; Barroeta, A. C.; Codony, R. Effect of dietary fat sources and zinc and selenium supplements on the composition and consumer acceptability of chicken meat. Poult. Sci. 2005, 84, $1129-1140$.

(35) Kingston, E. R.; Monahan, F. J.; Buckley, D. J.; Lynch, P. B. Lipid oxidation in cooked pork as affected by vitamin E, cooking and storage conditions. J. Food Sci. 1998, 63, 386-389.

(36) Conchillo, A.; Ansorena, D.; Astiasaran, I. Intensity of lipid oxidation and formation of cholesterol oxidation products during frozen storage of raw and cooked chicken. J. Sci. Food Agric. 2005, 85, 141146.

(37) Dal Bosco, A.; Castellini, C.; Bernardini, M. Nutritional quality of rabbit meat as affected by cooking procedure and dietary vitamin $\mathrm{E}$. J. Food Sci. 2001, 66, 1047-1051.

(38) Jensen, C.; Engberg, R.; Jakobsen, K.; Skibsted, L. H.; Bertelsen, G. Influence of the oxidative quality of dietary oil on broiler meat storage stability. Meat Sci. 1997, 47, 211-222.

Received for review April 28, 2010. Revised manuscript received July 14, 2010. Accepted July 20, 2010. This work was funded by the Ministerio de Educación y Ciencia (Spain) and by a research grant from the Instituto Danone awarded to A.T. 